\title{
Best proximity points for proximal contractive type mappings with $C$-class functions in $S$-metric spaces
}

\author{
Arslan Hojat Ansari ${ }^{1}$ and Jamnian Nantadilok ${ }^{2^{*}}$ (D)
}

"Correspondence:

jamnian52@|pru.ac.th

${ }^{2}$ Department of Mathematics,

Faculty of Science, Lampang

Rajabhat University, Lampang, 52100, Thailand

Full list of author information is available at the end of the article

\begin{abstract}
In this paper, we use the concept of $C$-class functions to establish the best proximity point results for a certain class of proximal contractive mappings in S-metric spaces. Our results extend and improve some known results in the literature. We give examples to analyze and support our main results.
\end{abstract}

MSC: Primary $47 \mathrm{H} 10$; secondary $54 \mathrm{H} 25$

Keywords: fixed points; proximity points; $G$-metric space; S-metric space; $B$-metric space; proximal contractive mapping; C-class function

\section{Introduction and preliminaries}

Consider the equation $T x=x$. If the equation $T x=x$ does not possess a solution, then we attempt to resolve the problem of finding an element $x$ such that $x$ is in proximity to $T x$. In fact, in the setting of a metric space $(X, d)$, if $T: A \rightarrow X$, then a best approximation theorem provides sufficient conditions that confirm the existence of an element $x_{0}$, known as the best approximant, such that $d\left(x_{0}, T x_{0}\right)=d\left(T x_{0}, A\right)$, where $d(A, B):=\inf \{d(x, y): x \in$ $A$ and $y \in B\}$ for any nonempty subsets $A$ and $B$ of $X$. Indeed, a classical best approximation theorem, due to Ky Fan [1], states that if $K$ is a nonempty compact convex subset of a Banach space $X$ and $T: K \rightarrow X$ is a single-valued continuous mapping, then there exists an element $x_{0} \in K$ such that $d\left(x_{0}, T x_{0}\right)=\inf \left\{d\left(y, T x_{0}\right): y \in K\right\}$, where $d$ is a metric on $X$. This result has been generalized by many authors (see[2-7]). In other words, if $A$ and $B$ are two nonempty subsets of a metric space $(X, d)$, then an element $x \in A$ is said to be a fixed point of a given map $T: A \rightarrow B$ if $T x=x$. Clearly, $T(A) \cap A \neq \emptyset$ is a necessary (but not sufficient) condition for the existence of a fixed point of $T$. If $T(A) \cap A=\emptyset$, then $d(x, T x)>0$ for all $x \in A$, that is, the set of fixed points of $T$ is empty. In such a situation, one often attempts to find an element $x$ which is in some sense closest to $T x$. Best proximity point analysis has been developed in this direction.

An element $x^{*} \in A$ is called a best proximity point of $T$ if

$$
d\left(x^{*}, T x^{*}\right)=d(A, B)
$$

Indeed, in view of the fact that $d(x, T x) \geq d(A, B)$ for all $x \in A$, the global minimum of the mapping $x \rightarrow d(x, T x)$ is attained at a best proximity point. Clearly, if the underlying

(c) The Author(s) 2017. This article is distributed under the terms of the Creative Commons Attribution 4.0 International License (http://creativecommons.org/licenses/by/4.0/), which permits unrestricted use, distribution, and reproduction in any medium, provided you give appropriate credit to the original author(s) and the source, provide a link to the Creative Commons license, and indicate if changes were made. 
mapping is self-mapping, then a best proximity point reduces to a fixed point. The goal of best proximity point theory is to furnish sufficient conditions that assure the existence of such points. For more details on this approach, we refer the reader to [8-19] and the references therein.

Mustafa and Sims [20] introduced the notion of G-metric and obtained some wellknown fixed point results in the setting of $G$-metric spaces. Many authors have obtained fixed point results in the context of G-metric spaces [21-28]. In 2007, Sedghi et al. [29, 30] introduced a $D^{*}$-metric space, which is a modification of $D$-metric spaces introduced by Dhage [31], and established common fixed point theorems in $D^{*}$-metric spaces. We note that every $G$-metric is a $D^{*}$-metric, but in general the converse is not true (see [32]). In 2012, Sedghi et al. [32] introduced the concept of an $S$-metric space, a modification of $D^{*}$ metric and $G$-metric spaces, and gave a generalization of fixed point theorems in $S$-metric spaces, but the best proximity point results in $S$-metric spaces still remain open. Recently, Ansari [33] introduced the concept of $C$-class functions which can be used to generalize many fixed point theorems in the literature (see, for example, [34]). Later, Nantadilok [35] obtained best proximity point results for a certain class of proximal contractive mappings in complete $S$-metric spaces. Inspired and motivated by Ansari [33] and Nantadilok [35], in this paper, we establish best proximity point results for proximal contractive type mappings with $C$-class functions in the setting of $S$-metric spaces. We also give examples to support our results.

Now we collect some necessary definitions and results in this direction. The notion of $S$-metric spaces is defined as follows.

Definition 1.1 (see [32]) Let $X$ be a nonempty set. An $S$-metric on $X$ is a function $S$ : $X^{3} \rightarrow[0, \infty)$ that satisfies the following conditions, for each $x, y, z, a \in X$.

(i) $S(x, y, z) \geq 0$;

(ii) $S(x, y, z)=0$ if and only if $x=y=z$;

(iii) $S(x, y, z) \leq S(x, x, a)+S(y, y, a)+S(z, z, a)$.

The function $S$ is called an $S$-metric on $X$, and the pair $(X, S)$ is called an $S$-metric space.

Remark 1.2 This notion is a modification of a $G$-metric space [20] and a $D^{*}$-metric space [29].

Lemma 1.3 (see [32]) Let $(X, S)$ be an S-metric space. Then $S(x, x, y)=S(y, y, x)$ for all $x, y \in X$.

Lemma 1.4 (see [36]) Let $(X, S)$ be an S-metric space. Then

$$
S(x, x, z) \leq 2 S(x, x, y)+S(y, y, z) \quad \text { and } \quad S(x, x, z) \leq 2 S(x, x, y)+S(z, z, y)
$$

for all $x, y, z \in X$.

Definition 1.5 (see [32]) Let $(X, S)$ be an $S$-metric space.

(i) A sequence $\left\{x_{n}\right\} \subset X$ is said to converge to $x \in X$ if $S\left(x_{n}, x_{n}, x\right) \rightarrow 0$ as $n \rightarrow \infty$. That is, for each $\varepsilon>0$, there exists $n_{0} \in \mathbb{N}$ such that for all $n \geq n_{0}$ we have $S\left(x_{n}, x_{n}, x\right)<\varepsilon$. We write $x_{n} \rightarrow x$ for brevity. 
(ii) A sequence $\left\{x_{n}\right\} \subset X$ is called a Cauchy sequence if $S\left(x_{n}, x_{n}, x_{m}\right) \rightarrow 0$ as $n, m \rightarrow \infty$. That is, for each $\varepsilon>0$, there exists $n_{0} \in \mathbb{N}$ such that for all $n, m \geq n_{0}$ we have $S\left(x_{n}, x_{n}, x_{m}\right)<\varepsilon$.

(iii) The $S$-metric space $(X, S)$ is said to be complete if every Cauchy sequence is a convergent sequence.

Some geometric examples for $S$-metric spaces can be seen in [32].

Definition 1.6 (see [37]) Let $X$ be a nonempty set. A $B$-metric on $X$ is a function $d$ : $X^{2} \rightarrow[0, \infty)$ if there exists a real umber $b \geq 1$ such that the following conditions hold for all $x, y, z \in X$.

(B1) $d(x, y)=0$ if and only if $x=y$.

(B2) $d(x, y)=d(y, x)$.

(B3) $d(x, y) \leq b[d(x, z)+d(y, z)]$.

The function $d$ is called a $B$-metric on $X$, and the pair $(X, d)$ is called a $B$-metric space.

Theorem 1.7 (see [38]) Let $(X, S)$ be an S-metric space, and let

$$
d(x, y)=S(x, x, y)
$$

for all $x, y \in X$. Then we have

(i) $d$ is a B-metric on $X$;

(ii) $x_{n} \rightarrow x$ in $(X, S)$ if and only if $x_{n} \rightarrow x$ in $(X, d)$;

(iii) $\left\{x_{n}\right\}$ is a Cauchy sequence in $(X, S)$ if and only if $\left\{x_{n}\right\}$ is a Cauchy sequence in $(X, d)$.

Now we recall the notion of $C$-class functions introduced in [33] as follows.

Definition 1.8 (see [33]) A mapping $f:[0, \infty)^{2} \rightarrow \mathbb{R}$ is called a $C$-class function if it is continuous and satisfies the following properties:

(1) $f(s, t) \leq s$

(2) $f(s, t)=s$ implies that either $s=0$, or $t=0$ for all $s, t \in[0, \infty)$.

We will denote the family of $C$-class functions as $\mathcal{C}$. Note that for some $F \in \mathcal{C}$, we have $F(0,0)=0$.

Example 1.9 (see [33]) The following functions $F:[0, \infty)^{2} \rightarrow \mathbb{R}$ are elements of $\mathcal{C}$, for all $s, t \in[0, \infty)$ :

(1) $F(s, t)=s-t, F(s, t)=s \Rightarrow t=0$;

(2) $F(s, t)=m s, 0<m<1, F(s, t)=s \Rightarrow s=0$;

(3) $F(s, t)=\frac{s}{(1+t)^{r}}, r \in(0, \infty), F(s, t)=s \Rightarrow s=0$ or $t=0$;

(4) $F(s, t)=\log \left(t+a^{s}\right) /(1+t), a>1, F(s, t)=s \Rightarrow s=0$ or $t=0$;

(5) $F(s, t)=\ln \left(1+a^{s}\right) / 2, a>e, F(s, 1)=s \Rightarrow s=0$;

(6) $F(s, t)=(s+l)^{\left(1 /(1+t)^{r}\right)}-l, l>1, r \in(0, \infty), F(s, t)=s \Rightarrow t=0$;

(7) $F(s, t)=s \log _{t+a} a, a>1, F(s, t)=s \Rightarrow s=0$ or $t=0$;

(8) $F(s, t)=s-\left(\frac{1+s}{2+s}\right)\left(\frac{t}{1+t}\right), F(s, t)=s \Rightarrow t=0$;

(9) $F(s, t)=s \beta(s), \beta:[0, \infty) \rightarrow[0,1)$, and is continuous, $F(s, t)=s \Rightarrow s=0$; 
(10) $F(s, t)=s-\frac{t}{k+t}, F(s, t)=s \Rightarrow t=0$;

(11) $F(s, t)=s-\varphi(s), F(s, t)=s \Rightarrow s=0$, where $\varphi:[0, \infty) \rightarrow[0, \infty)$ is a continuous function such that $\varphi(t)=0 \Leftrightarrow t=0$;

(12) $F(s, t)=\operatorname{sh}(s, t), F(s, t)=s \Rightarrow s=0$, where $h:[0, \infty) \times[0, \infty) \rightarrow[0, \infty)$ is a continuous function such that $h(t, s)<1$ for all $t, s>0$;

(13) $F(s, t)=s-\left(\frac{2+t}{1+t}\right) t, F(s, t)=s \Rightarrow t=0$;

(14) $F(s, t)=s-\left(\frac{1+s}{2+s}\right)\left(\frac{t}{1+t}\right), F(s, t)=s \Rightarrow t=0$;

(15) $F(s, t)=\sqrt[n]{\ln \left(1+s^{n}\right)}, F(s, t)=s \Rightarrow s=0$;

(16) $F(s, t)=\frac{s}{(1+s)^{r}} ; r \in(0, \infty), F(s, t)=s \Rightarrow s=0$;

(17) $F(s, t)=\vartheta(s) ; \vartheta: \mathbb{R}^{+} \times \mathbb{R}^{+} \rightarrow \mathbb{R}$ is a generalized Mizoguchi-Takahashi type function, $F(s, t)=s \Rightarrow s=0$.

Definition 1.10 (see [39]) A function $\psi:[0, \infty) \rightarrow[0, \infty)$ is called an altering distance function if the following properties are satisfied:

(i) $\psi$ is nondecreasing and continuous,

(ii) $\psi(t)=0$ if and only if $t=0$.

We let $\Psi$ denote the class of altering distance functions.

Definition 1.11 (see [39]) An ultra altering distance function is a continuous, nondecreasing mapping $\psi:[0, \infty) \rightarrow[0, \infty)$ such that $\psi(t)>0, t>0$ and $\psi(0) \geq 0$.

We let $\Phi_{u}$ denote the set of all ultra altering distance functions. We note that every $S$-metric on $X$ induces a metric $d_{S}$ on $X$ defined by

$$
d_{S}(x, y)=S(x, x, y)+S(y, y, x)
$$

for all $x, y \in X$.

We show that a metric $d_{S}$ on $X$ defined by (1) is a $B$-metric on $X$. Conditions (B1) and (B2) are easy to check. It follows from the definition of $S$-metric and Lemma 1.3 that

$$
\begin{aligned}
d_{S}(x, y)= & S(x, x, y)+S(y, y, x) \\
\leq & S(x, x, z)+S(x, x, z)+S(y, y, z) \\
& +S(y, y, z)+S(y, y, z)+S(x, x, z) \\
= & d S(x, z)+d_{S}(y, z)+S(x, x, z)+S(y, y, z) \\
\leq & d_{S}(x, z)+d_{S}(y, z)+2 S(x, x, z)+2 S(y, y, z) \\
= & 2\left[d_{S}(x, z)+d_{S}(y, z)\right] .
\end{aligned}
$$

This shows that $d_{S}$ is a $B$-metric.

Definition 1.12 (see [35]) Let $(X, S)$ be an $S$-metric space, and let $A$ and $B$ be two nonempty subsets of $X$. Then $B$ is said to be approximately compact with respect to $A$ if every sequence $\left\{y_{n}\right\}$ in $B$, satisfying the condition $d_{S}\left(x, y_{n}\right) \rightarrow d_{S}(x, B)$ for some $x$ in $A$, has a convergent subsequence. 
Let $\Phi$ denote the class of all functions $\varphi:[0, \infty) \rightarrow[0, \infty)$ which satisfy

1. $\varphi$ continuous and nondecreasing,

2. $\varphi(t)=0$ if and only if $t=0$,

3. $\varphi(t+s) \leq \varphi(t)+\varphi(s), \forall t, s \in[0, \infty)$.

Definition 1.13 (see [35]) Let $A$ and $B$ be two nonempty subsets of an $S$-metric space $(X, S)$. Let $T: A \rightarrow B$ be a nonself-mapping. We say that $T$ is an $S$ - $\varphi$ - $\psi$-proximal contractive mapping, if for all $x, y, u, v \in A$,

$$
\left.\begin{array}{l}
d_{S}(u, T x)=d_{S}(A, B) \\
d_{S}(v, T y)=d_{S}(A, B)
\end{array}\right\} \Rightarrow \varphi(S(u, u, v)) \leq \varphi(S(x, x, y))-\psi(S(x, x, y))
$$

holds, where $\varphi \in \Phi$ and $\psi \in \Psi$.

Definition 1.14 Let $A$ and $B$ be two nonempty subsets of an $S$-metric space $(X, S)$. An element $x^{*} \in A$ is said to be a best proximity point of a nonself-mapping $T$ if $d_{S}\left(x^{*}, T x^{*}\right)=$ $d_{S}(A, B)$.

The main result obtained in [35] is the following best proximity point theorem.

Theorem 1.15 (see [35]) Let $A, B$ be two nonempty subsets of an $S$-metric space $(X, S)$ such that $(A, S)$ is a complete $S$-metric space, $A_{0}$ is nonempty, and $B$ is approximately compact with respect to $A$. Assume that $T: A \rightarrow B$ is an $S-\varphi-\psi$-proximal contractive mapping such that $T\left(A_{0}\right) \subseteq B_{0}$. Then $T$ has a unique best proximity point; that is, there exists a unique element $z \in A$ such that $d_{S}(z, T z)=d_{S}(A, B)$.

\section{Main results}

Let $(X, S)$ be an $S$-metric space. Suppose that $A$ and $B$ are nonempty subsets of an $S$-metric space $(X, S)$. We will use the following notations:

$$
\begin{aligned}
& A_{0}=\left\{a \in A: d_{S}(a, b)=d_{S}(A, B) \text { for some } b \in B\right\} \quad \text { and } \\
& B_{0}=\left\{b \in B: d_{S}(a, b)=d_{S}(A, B) \text { for some } a \in A\right\},
\end{aligned}
$$

where $d_{S}(A, B)=\inf \left\{d_{S}(x, y): x \in A, y \in B\right\}$.

We introduce the following definitions.

Definition 2.1 Let $A$ and $B$ be two nonempty subsets of an $S$-metric space $(X, S)$. Let $T: A \rightarrow B$ be a nonself-mapping. We say that $T$ is an $S-(F, \varphi, \psi)$-proximal contractive mapping, if for all $x, y, u, v \in A$,

$$
\begin{aligned}
& \left.\begin{array}{l}
d_{S}(u, T x)=d_{S}(A, B) \\
d_{S}(v, T y)=d_{S}(A, B)
\end{array}\right\} \\
& \Rightarrow \varphi(S(u, u, v)) \leq F(\varphi(S(x, x, y)), \psi(S(x, x, y)))
\end{aligned}
$$

holds, where $F \in \mathcal{C}, \varphi \in \Phi$ and $\psi \in \Phi_{u}$. 
Definition 2.2 Let $A$ and $B$ be two nonempty subsets of an $S$-metric space $(X, S)$. Let $T: A \rightarrow B$ be a nonself-mapping. We say that $T$ is an $S-(F, \varphi, \psi)$-sum-proximal contractive mapping, if for all $x, y, u, v \in A$,

$$
\begin{aligned}
& \left.\begin{array}{l}
d_{S}(u, T x)=d_{S}(A, B) \\
d_{S}\left(u^{*}, T u\right)=d_{S}(A, B) \\
d_{S}(v, T y)=d_{S}(A, B)
\end{array}\right\} \\
& \Rightarrow \varphi(S(u, u, v)) \leq F\left(\varphi\left(m_{\left(u, u^{*}, v, x, y\right)}\right), \psi\left(m_{\left(u, u^{*}, v, x, y\right)}\right)\right)
\end{aligned}
$$

holds, where $F \in \mathcal{C}, \varphi \in \Phi, \psi \in \Phi_{u}$ and

$$
m_{\left(u, u^{*}, v, x, y\right)}=\frac{1}{a+b+c+d}\left[a S(u, u, x)+b S(x, x, y)+c S\left(y, y, u^{*}\right)+d S(y, y, v)\right]
$$

with $a, b, c, d \geq 0$ and $a+b+c+d>0$.

We note that these kind of generalizations make sense, since they extend and cover those corresponding classes of proximal contractive mappings defined in [35]. We state and prove our main results.

Theorem 2.3 Let $A, B$ be two nonempty subsets of an $S$-metric space $(X, S)$ such that $(A, S)$ is a complete $S$-metric space, $A_{0}$ is nonempty, and $B$ is approximately compact with respect to $A$. Assume that $T: A \rightarrow B$ is an $S-(F, \varphi, \psi)$-proximal contractive mapping such that $T\left(A_{0}\right) \subseteq B_{0}$. Then $T$ has a unique best proximity point; that is, there exists a unique element $z \in A$ such that $d_{S}(z, T z)=d_{S}(A, B)$.

Proof Since the subset $A_{0}$ is not empty, we take $x_{0}$ in $A_{0}$. Taking $T x_{0} \in T\left(A_{0}\right) \subseteq B_{0}$ into account, we can find $x_{1} \in A_{0}$ such that $d_{S}\left(x_{1}, T x_{0}\right)=d_{S}(A, B)$. Further, since $T x_{1} \in T\left(A_{0}\right) \subseteq$ $B_{0}$, it follows that there is an element $x_{2}$ in $A_{0}$ such that $d_{S}\left(x_{2}, T x_{1}\right)=d_{S}(A, B)$. Recursively, we obtain a sequence $\left\{x_{n}\right\}$ in $A_{0}$ satisfying

$$
d_{S}\left(x_{n+1}, T x_{n}\right)=d_{S}(A, B), \quad \forall n \in \mathbb{N} \cup\{0\} .
$$

This shows that

$$
\begin{aligned}
& d_{S}(u, T x)=d_{S}(A, B), \\
& d_{S}(v, T y)=d_{S}(A, B),
\end{aligned}
$$

where $u=x_{n}, x=x_{n-1}, v=x_{n+1}$ and $y=x_{n}$. Therefore from (4) we have

$$
\begin{aligned}
\varphi\left(S\left(x_{n}, x_{n}, x_{n+1}\right)\right) & \leq F\left(\varphi\left(S\left(x_{n-1}, x_{n-1}, x_{n}\right)\right), \psi\left(S\left(x_{n-1}, x_{n-1}, x_{n}\right)\right)\right) \\
& \leq \varphi\left(S\left(x_{n-1}, x_{n-1}, x_{n}\right)\right)
\end{aligned}
$$

which implies

$$
S\left(x_{n}, x_{n}, x_{n+1}\right) \leq S\left(x_{n-1}, x_{n-1}, x_{n}\right) .
$$


So, the sequence $\left\{S\left(x_{n}, x_{n}, x_{n+1}\right)\right\}$ is a decreasing sequence in $\mathbb{R}^{+}$and thus it is convergent to $t \in \mathbb{R}^{+}$. We claim that $t=0$. Suppose, on the contrary, that $t>0$. Taking the limit as $n \rightarrow \infty$ in (8), we get

$$
\varphi(t) \leq F(\varphi(t), \psi(t))
$$

which implies $\varphi(t)=0$ or $\psi(t)=0$. That is, $t=0$, which is a contradiction. Hence, $t=0$. That is,

$$
\lim _{n \rightarrow \infty} S\left(x_{n}, x_{n}, x_{n+1}\right)=0
$$

We will show that $\left\{x_{n}\right\}_{n=0}^{\infty}$ is an $S$-Cauchy sequence. Suppose, on the contrary, that there exist $\varepsilon>0$ and a subsequence $\left\{x_{n_{k}}\right\}$ of $\left\{x_{n}\right\}$ such that

$$
S\left(x_{m_{k}}, x_{m_{k}}, x_{n_{k}}\right) \geq \varepsilon
$$

with $n_{k} \geq m_{k}>k$. Further, corresponding to $m_{k}$, we can choose $n_{k}$ in such a way that it is the smallest integer with $n_{k}>m_{k}$ and it satisfies (11). Hence,

$$
S\left(x_{m_{k}}, x_{m_{k}}, x_{n_{k}-1}\right)<\varepsilon
$$

Set $\rho_{n}=2 S\left(x_{n}, x_{n}, x_{n-1}\right)$. By Lemmas 1.3 and 1.4 , we have

$$
\begin{aligned}
\varepsilon & \leq S\left(x_{m_{k}}, x_{m_{k}}, x_{n_{k}}\right)=S\left(x_{n_{k}}, x_{n_{k}}, x_{m_{k}}\right) \\
& \leq 2 S\left(x_{n_{k}}, x_{n_{k}}, x_{n_{k}-1}\right)+S\left(x_{m_{k}}, x_{m_{k}}, x_{n_{k}-1}\right) \\
& \leq 2 S\left(x_{n_{k}}, x_{n_{k}}, x_{n_{k}-1}\right)+\varepsilon \\
& =\rho_{n_{k}}+\varepsilon .
\end{aligned}
$$

Letting $k \rightarrow \infty$ in (13), we derive that

$$
\lim _{k \rightarrow \infty} S\left(x_{m_{k}}, x_{m_{k}}, x_{n_{k}}\right)=\varepsilon
$$

Again, by Lemmas 1.3 and 1.4, we obtain the following inequalities:

$$
\begin{aligned}
S\left(x_{m_{k}}, x_{m_{k}}, x_{n_{k}}\right) \leq & 2 S\left(x_{m_{k}}, x_{m_{k}}, x_{m_{k}-1}\right)+S\left(x_{n_{k}}, x_{n_{k}}, x_{m_{k}-1}\right) \\
\leq & 2 S\left(x_{m_{k}}, x_{m_{k}}, x_{m_{k}-1}\right)+2 S\left(x_{n_{k}}, x_{n_{k}}, x_{n_{k}-1}\right) \\
& +S\left(x_{m_{k}-1}, x_{m_{k}-1}, x_{n_{k}-1}\right) \\
= & \left(\rho_{m_{k}}+\rho_{n_{k}}\right)+S\left(x_{m_{k}-1}, x_{m_{k}-1}, x_{n_{k}-1}\right)
\end{aligned}
$$

and

$$
\begin{aligned}
S\left(x_{m_{k}-1}, x_{m_{k}-1}, x_{n_{k}-1}\right) & \leq 2 S\left(x_{m_{k}-1}, x_{m_{k}-1}, x_{m_{k}}\right)+S\left(x_{n_{k}-1}, x_{n_{k}-1}, x_{m_{k}}\right) \\
& \leq 2 S\left(x_{m_{k}-1}, x_{m_{k}-1}, x_{m_{k}}\right)+2 S\left(x_{n_{k}-1}, x_{n_{k}-1}, x_{n_{k}}\right)
\end{aligned}
$$




$$
\begin{aligned}
& +S\left(x_{m_{k}}, x_{m_{k}}, x_{n_{k}}\right) \\
= & \left(\rho_{m_{k}}+\rho_{n_{k}}\right)+S\left(x_{m_{k}}, x_{m_{k}}, x_{n_{k}}\right) .
\end{aligned}
$$

Letting $k \rightarrow \infty$ in (16) and applying (15), we find that

$$
\lim _{k \rightarrow \infty} S\left(x_{m_{k}-1}, x_{m_{k}-1}, x_{n_{k}-1}\right)=\varepsilon
$$

From (4) with $u=x_{m_{k}}, x=x_{m_{k}-1}, v=x_{n_{k}}$ and $y=x_{n_{k}-1}$, we have

$$
\begin{aligned}
& \varphi\left(S\left(x_{m_{k}}, x_{m_{k}}, x_{n_{k}}\right)\right) \leq F\left(\varphi\left(S\left(x_{m_{k}-1}, x_{m_{k}-1}, x_{n_{k}-1}\right)\right),\right. \\
& \left.\psi\left(S\left(x_{m_{k}-1}, x_{m_{k}-1}, x_{n_{k}-1}\right)\right)\right) .
\end{aligned}
$$

Taking the limit as $k \rightarrow \infty$ in the above inequality, we obtain

$$
\varphi(\varepsilon) \leq F(\varphi(\varepsilon), \psi(\varepsilon))
$$

which implies $\varphi(\varepsilon)=0$ or $\psi(\varepsilon)=0$. That is, $\varepsilon=0$, which is contradiction. Thus,

$$
\lim _{m, n \rightarrow \infty} S\left(x_{m}, x_{m}, x_{n}\right)=0 .
$$

That is, $\left\{x_{n}\right\}_{n=0}^{\infty}$ is a Cauchy sequence. Since $(A, S)$ is a complete $S$-metric space, there exists $z \in A$ such that $x_{n} \rightarrow z$ as $n \rightarrow \infty$. On the other hand, for all $n \in \mathbb{N}$, we can write

$$
\begin{aligned}
d_{S}(z, B) & \leq d_{S}\left(z, T x_{n}\right) \\
& \leq d_{S}\left(z, x_{n+1}\right)+d_{S}\left(x_{n+1}, T x_{n}\right) \\
& =d_{S}\left(z, x_{n+1}\right)+d_{S}(A, B) .
\end{aligned}
$$

Taking the limit as $n \rightarrow \infty$ in the above inequality, we obtain

$$
\lim _{n \rightarrow \infty} d_{S}\left(z, T x_{n}\right)=d_{S}(z, B)=d_{S}(A, B) .
$$

Since $B$ is approximately compact with respect to $A$, the sequence $\left\{T x_{n}\right\}$ has a subsequence $\left\{T x_{n_{k}}\right\}$ that converges to some $y^{*} \in B$. Hence,

$$
d_{S}\left(z, y^{*}\right)=\lim _{k \rightarrow \infty} d_{S}\left(x_{n_{k}+1}, T x_{n_{k}}\right)=d_{S}(A, B)
$$

and so $z \in A_{0}$. Now, since $T z \in T\left(A_{0}\right) \subseteq B_{0}$, there exists $w \in A_{0}$ such that $d_{S}(w, T z)=$ $d_{S}(A, B)$.

From (4) with $u=x_{n+1}, x=x_{n}, v=w$ and $y=z$, we have

$$
\varphi\left(S\left(x_{n+1}, x_{n+1}, w\right)\right) \leq F\left(\varphi\left(S\left(x_{n}, x_{n}, z\right)\right), \psi\left(S\left(x_{n}, x_{n}, z\right)\right)\right) .
$$

Taking the limit as $n \rightarrow \infty$, we get

$$
\varphi(S(z, z, w)) \leq F(\varphi(0), \psi(0)) \leq \varphi(0)=0 .
$$


This implies $S(z, z, w)=0$. That is, $w=z$. Thus $d_{S}(z, T z)=d_{S}(A, B)$. Therefore $T$ has a best proximity point. To prove uniqueness, suppose that $p \neq q$ such that $d_{S}(p, T p)=d_{S}(A, B)$ and $d_{S}(q, T q)=d_{S}(A, B)$. Now, by (4) with $u=x=p$ and $v=y=q$, we get

$$
\varphi(S(p, p, q)) \leq F(\varphi(S(p, p, q)), \psi(S(p, p, q)))
$$

which implies $\varphi(S(p, p, q))=0$ or $\psi(S(p, p, q))=0$; that is, $p=q$.

Example 2.4 Let $X=[0, \infty)$. Define an $S$-metric on $X$ by

$$
S(x, y, z)=\frac{1}{12}(|x-z|+|y-z|) .
$$

From (1), we get $d_{S}(x, y)=\frac{1}{3}|x-y|$. Let $A=[1,4]$ and $B=[7,10]$. We define $T: A \rightarrow B$ by

$$
T(x)= \begin{cases}7 & \text { if } x=4 \\ x+6 & \text { otherwise }\end{cases}
$$

Let $F(s, t)=s-t$ for all $s, t \in[0, \infty)$. Also define $\varphi, \psi:[0, \infty) \rightarrow[0, \infty)$ by $\varphi(t)=t$ and $\psi(t)=\frac{1}{2} t$. Clearly, $d_{S}(A, B)=1, A_{0}=\{4\}, B_{0}=\{7\}$ and $T\left(A_{0}\right) \subseteq B_{0}$. Let $d_{S}(u, T x)=d_{S}(A, B)$ and $d_{S}(v, T y)=d_{S}(A, B)$, then $u=v=4, x=1,4$, and $y=1,4$. Now since $u=v=4$, $\varphi(S(u, u, v))=0$. Hence,

$$
\begin{aligned}
F(\varphi(S(x, x, y)), \psi(S(x, x, y)))-\varphi(S(u, u, v)) & =\varphi(S(x, x, y))-\psi(S(x, x, y))-0 \\
& =S(x, x, y)-\frac{1}{2}(S(x, x, y)) \\
& =\frac{1}{6}|x-y|-\frac{1}{12}|x-y| \\
& =\frac{1}{12}|x-y| \geq 0 .
\end{aligned}
$$

Therefore, we have

$$
\varphi(S(u, u, v)) \leq F(\varphi(S(x, x, y)), \psi(S(x, x, y))) .
$$

That is,

$$
\left.\begin{array}{l}
d_{S}(u, T x)=d_{S}(A, B) \\
d_{S}(v, T y)=d_{S}(A, B)
\end{array}\right\} \quad \Rightarrow \quad \varphi(S(u, u, v)) \leq F(\varphi(S(x, x, y)), \psi(S(x, x, y))) .
$$

Thus $T$ is an $S$ - $(F, \varphi, \psi)$-proximal contractive mapping. All the conditions of Theorem 2.3 hold true, and $T$ has a unique best proximity point. Here, $z=4$ is the unique best proximity point of $T$.

Remark 2.5 If we take $F(s, t)=s-t$ in Theorem 2.3, then our result reduces to Theorem 2.3 in [35]. 
Theorem 2.6 Let $A, B$ be two nonempty subsets of an $S$-metric space $(X, S)$ such that $(A, S)$ is a complete $S$-metric space, $A_{0}$ is nonempty, and $B$ is approximately compact with respect to $A$. Assume that $T: A \rightarrow B$ is an $S$ - $(F, \varphi, \psi)$-sum-proximal contractive mapping such that $T\left(A_{0}\right) \subseteq B_{0}$. Then $T$ has a unique best proximity point; that is, there exists a unique element $z \in A$ such that $d_{S}(z, T z)=d_{S}(A, B)$.

Proof Since the subset $A_{0}$ is not empty, we take $x_{0}$ in $A_{0}$. Taking $T x_{0} \in T\left(A_{0}\right) \subseteq B_{0}$ into account, we can find $x_{1} \in A_{0}$ such that $d_{S}\left(x_{1}, T x_{0}\right)=d_{S}(A, B)$. Further, since $T x_{1} \in T\left(A_{0}\right) \subseteq$ $B_{0}$, it follows that there is an element $x_{2}$ in $A_{0}$ such that $d_{S}\left(x_{2}, T x_{1}\right)=d_{S}(A, B)$. Recursively, we obtain a sequence $\left\{x_{n}\right\}$ in $A_{0}$ satisfying

$$
d_{S}\left(x_{n+1}, T x_{n}\right)=d_{S}(A, B), \quad \forall n \in \mathbb{N} \cup\{0\} .
$$

From (5) with $x=x_{n}, u=x_{n+1}, u^{*}=x_{n+2}, y=x_{n+1}$ and $v=x_{n+2}$, and Lemma 1.3, we have

$$
\begin{aligned}
& \varphi\left(S\left(x_{n+1}, x_{n+1}, x_{n+2}\right)\right) \\
& \leq F\left(\varphi \left(\frac { 1 } { a + b + c + d } \left[a S\left(x_{n+1}, x_{n+1}, x_{n}\right)+b S\left(x_{n}, x_{n}, x_{n+1}\right)\right.\right.\right. \\
&\left.\left.+c S\left(x_{n+1}, x_{n+1}, x_{n+2}\right)+d S\left(x_{n+1}, x_{n+1}, x_{n+2}\right)\right]\right), \\
& \psi\left(\frac { 1 } { a + b + c + d } \left[a S\left(x_{n+1}, x_{n+1}, x_{n}\right)+b S\left(x_{n}, x_{n}, x_{n+1}\right)\right.\right. \\
&\left.\left.\left.+c S\left(x_{n+1}, x_{n+1}, x_{n+2}\right)+d S\left(x_{n+1}, x_{n+1}, x_{n+2}\right)\right]\right)\right) \\
& \leq \varphi\left(\frac { 1 } { a + b + c + d } \left[(a+b) S\left(x_{n+1}, x_{n+1}, x_{n}\right)\right.\right. \\
&\left.\left.\quad+(c+d) S\left(x_{n+1}, x_{n+1}, x_{n+2}\right)\right]\right),
\end{aligned}
$$

which implies

$$
S\left(x_{n}, x_{n}, x_{n+1}\right) \leq S\left(x_{n-1}, x_{n-1}, x_{n}\right) .
$$

So, the sequence $\left\{S\left(x_{n}, x_{n}, x_{n+1}\right)\right\}$ is a decreasing sequence in $\mathbb{R}^{+}$and thus it is convergent to $t \in \mathbb{R}^{+}$. We claim that $t=0$. Suppose, on the contrary, that $t>0$. Taking the limit as $n \rightarrow \infty$ in (29), we get

$$
\varphi(t) \leq F(\varphi(t), \psi(t))
$$

which implies $\varphi(t)=0$ or $\psi(t)=0$. That is, $t=0$, which is a contradiction. Hence, $t=0$. That is,

$$
\lim _{n \rightarrow \infty} S\left(x_{n}, x_{n}, x_{n+1}\right)=0 .
$$

We will show that $\left\{x_{n}\right\}_{n=0}^{\infty}$ is an $S$-Cauchy sequence. Suppose, on the contrary, that there exist $\varepsilon>0$ and a subsequence $\left\{x_{n_{k}}\right\}$ of $\left\{x_{n}\right\}$ such that

$$
S\left(x_{m_{k}}, x_{m_{k}}, x_{n_{k}}\right) \geq \varepsilon
$$


with $n_{k} \geq m_{k}>k$. Further, corresponding to $m_{k}$, we can choose $n_{k}$ in such a way that it is the smallest integer with $n_{k}>m_{k}$ satisfying (32). Hence,

$$
S\left(x_{m_{k}}, x_{m_{k}}, x_{n_{k}-1}\right)<\varepsilon
$$

Set $\rho_{n}=2 S\left(x_{n}, x_{n}, x_{n-1}\right)$. By Lemmas 1.3 and 1.4 , we have

$$
\begin{aligned}
\varepsilon & \leq S\left(x_{m_{k}}, x_{m_{k}}, x_{n_{k}}\right)=S\left(x_{n_{k}}, x_{n_{k}}, x_{m_{k}}\right) \\
& \leq 2 S\left(x_{n_{k}}, x_{n_{k}}, x_{n_{k}-1}\right)+S\left(x_{m_{k}}, x_{m_{k}}, x_{n_{k}-1}\right) \\
& \leq 2 S\left(x_{n_{k}}, x_{n_{k}}, x_{n_{k}-1}\right)+\varepsilon \\
& =\rho_{n_{k}}+\varepsilon .
\end{aligned}
$$

Letting $k \rightarrow \infty$, we derive

$$
\lim _{k \rightarrow \infty} S\left(x_{m_{k}}, x_{m_{k}}, x_{n_{k}}\right)=\varepsilon
$$

Again, by using Lemmas 1.3 and 1.4, we obtain the following inequalities:

$$
\begin{aligned}
S\left(x_{m_{k}}, x_{m_{k}}, x_{n_{k}}\right) \leq & 2 S\left(x_{m_{k}}, x_{m_{k}}, x_{m_{k}-1}\right)+S\left(x_{n_{k}}, x_{n_{k}}, x_{m_{k}-1}\right) \\
\leq & 2 S\left(x_{m_{k}}, x_{m_{k}}, x_{m_{k}-1}\right)+2 S\left(x_{n_{k}}, x_{n_{k}}, x_{n_{k}-1}\right) \\
& +S\left(x_{m_{k}-1}, x_{m_{k}-1}, x_{n_{k}-1}\right) \\
= & \left(\rho_{m_{k}}+\rho_{n_{k}}\right)+S\left(x_{m_{k}-1}, x_{m_{k}-1}, x_{n_{k}-1}\right)
\end{aligned}
$$

and

$$
\begin{aligned}
S\left(x_{m_{k}-1}, x_{m_{k}-1}, x_{n_{k}-1}\right) \leq & 2 S\left(x_{m_{k}-1}, x_{m_{k}-1}, x_{m_{k}}\right)+S\left(x_{n_{k}-1}, x_{n_{k}-1}, x_{m_{k}}\right) \\
\leq & 2 S\left(x_{m_{k}-1}, x_{m_{k}-1}, x_{m_{k}}\right)+2 S\left(x_{n_{k}-1}, x_{n_{k}-1}, x_{n_{k}}\right) \\
& +S\left(x_{m_{k}}, x_{m_{k}}, x_{n_{k}}\right) \\
= & \left(\rho_{m_{k}}+\rho_{n_{k}}\right)+S\left(x_{m_{k}}, x_{m_{k}}, x_{n_{k}}\right) .
\end{aligned}
$$

Letting $k \rightarrow \infty$ in (36) and (37) and applying (35), we find that

$$
\lim _{k \rightarrow \infty} S\left(x_{m_{k}-1}, x_{m_{k}-1}, x_{n_{k}-1}\right)=\varepsilon .
$$

From (5) with $x=x_{m_{k}-1}, u=x_{m_{k}}, u^{*}=x_{m_{k}-1}, y=x_{n_{k}-1}, v=x_{n_{k}}$, we have

$$
\begin{aligned}
& \varphi\left(S\left(x_{m_{k}}, x_{m_{k}}, x_{n_{k}}\right)\right) \\
& \leq \\
& \quad F\left(\varphi \left(\frac { 1 } { a + b + c + d } \left[a S\left(x_{m_{k}}, x_{m_{k}}, x_{m_{k}-1}\right)+b S\left(x_{m_{k}-1}, x_{m_{k}-1}, x_{n_{k}-1}\right)\right.\right.\right. \\
& \left.\left.\quad+c S\left(x_{n_{k}-1}, x_{n_{k}-1}, x_{m_{k}-1}\right)+d S\left(x_{n_{k}-1}, x_{n_{k}-1}, x_{n_{k}}\right)\right]\right)
\end{aligned}
$$




$$
\begin{aligned}
& \psi\left(\frac { 1 } { a + b + c + d } \left[a S\left(x_{m_{k}}, x_{m_{k}}, x_{m_{k}-1}\right)+b S\left(x_{m_{k}-1}, x_{m_{k}-1}, x_{n_{k}-1}\right)\right.\right. \\
& \left.\left.\left.+c S\left(x_{n_{k}-1}, x_{n_{k}-1}, x_{m_{k}-1}\right)+d S\left(x_{n_{k}-1}, x_{n_{k}-1}, x_{n_{k}}\right)\right]\right)\right) .
\end{aligned}
$$

Taking the limit as $k \rightarrow \infty$ in the above inequality, we obtain

$$
\varphi(\varepsilon) \leq F(\varphi(\varepsilon), \psi(\varepsilon))
$$

which implies $\varphi(\varepsilon)=0$ or $\psi(\varepsilon)=0$. That is, $\varepsilon=0$, which is a contradiction. Thus,

$$
\lim _{m, n \rightarrow \infty} S\left(x_{m}, x_{m}, x_{n}\right)=0
$$

This proves that $\left\{x_{n}\right\}$ is a Cauchy sequence in an $S$-metric space $(X, S)$. Since $(A, S)$ is a complete metric space, there exists $z \in A$ such that $\left\{x_{n}\right\}$ converges to $z$. As in the proof of Theorem 2.3, we have $d_{S}(w, T z)=d_{S}(A, B)$ for some $w \in A_{0}$. From (5) with $x=x_{n-1}, u=x_{n}$, $u^{*}=x_{n+1}, y=z$ and $v=w$, we have

$$
\begin{aligned}
& \varphi\left(S\left(x_{n}, x_{n}, w\right)\right) \\
& \leq F\left(\varphi \left(\frac { 1 } { a + b + c + d } \left[a S\left(x_{n}, x_{n}, x_{n-1}\right)+b S\left(x_{n-1}, x_{n-1}, z\right)\right.\right.\right. \\
&\left.\left.+c S\left(z, z, x_{n+1}\right)+d S(z, z, w)\right]\right) \\
& \psi\left(\frac { 1 } { a + b + c + d } \left[a S\left(x_{n}, x_{n}, x_{n-1}\right)+b S\left(x_{n-1}, x_{n-1}, z\right)\right.\right. \\
&\left.\left.\left.+c S\left(z, z, x_{n+1}\right)+d S(z, z, w)\right]\right)\right) .
\end{aligned}
$$

Taking the limit as $n \rightarrow \infty$ in the above inequality, we get

$$
\begin{aligned}
& \varphi(S(z, z, w)) \\
& \quad \leq F\left(\varphi\left(\frac{d}{a+b+c+d} d S(z, z, w)\right), \varphi\left(\frac{d}{a+b+c+d} S(z, z, w)\right)\right) \\
& \quad \leq \varphi\left(\frac{d}{a+b+c+d} S(z, z, w)\right) \leq \varphi(S(z, z, w)),
\end{aligned}
$$

which implies $\varphi\left(\frac{d}{a+b+c+d} S(z, z, w)\right)=0$ or $\psi\left(\frac{d}{a+b+c+d} S(z, z, w)\right)=0$. This means $S(z, z, w)=0$. Hence, $w=z$; that is, $d_{S}(z, T z)=d_{S}(w, T z)=d_{S}(A, B)$. Thus $T$ has a best proximity point. To prove uniqueness, suppose that $p \neq q, d_{S}(p, T p)=d_{S}(A, B)$ and $d_{S}(q, T q)=d_{S}(A, B)$. Now by (5) with $x=u=u^{*}=p$ and $y=v=q$, we have

$$
\begin{aligned}
& \varphi(S(p, p, q)) \\
& \quad \leq F\left(\varphi\left(\frac{b+c}{a+b+c+d} S(p, p, q)\right), \psi\left(\frac{b+c}{a+b+c+d} S(p, p, q)\right)\right) \\
& \quad \leq \varphi\left(\frac{b+c}{a+b+c+d} S(p, p, q)\right) \leq \varphi(S(p, p, q)),
\end{aligned}
$$


which implies $\varphi\left(\frac{b+c}{a+b+c+d} S(p, p, q)\right)=0$ or $\psi\left(\frac{b+c}{a+b+c+d} S(p, p, q)\right)=0$, so $S(p, p, q)=0$. Hence $p=q$, that is, $T$ has the unique best proximity point.

Example 2.7 Similar to Example 2.4. Let $X=[0, \infty)$. We define an $S$-metric on $X$ by

$$
S(x, y, z)=\frac{1}{4}(|x-z|+|y-z|) .
$$

From (1), we get $d_{S}(x, y)=|x-y|$. Let $A=[2,6]$ and $B=[7,11]$. We define $T: A \rightarrow B$ by

$$
T(x)= \begin{cases}7 & \text { if } x=6 \\ x+5 & \text { otherwise }\end{cases}
$$

Let $F(s, t)=s-\frac{t}{t+k}$ for all $s, t \in[0, \infty)$. This is a $C$-class function. Also define $\varphi, \psi:[0, \infty) \rightarrow$ $[0, \infty)$ by $\varphi(t)=t$ and $\psi(t)=\frac{1}{2} t$. Clearly, $d_{S}(A, B)=1, A_{0}=\{6\}, B_{0}=\{7\}$ and $T\left(A_{0}\right) \subseteq B_{0}$. Let $d_{S}(u, T x)=d_{S}(A, B), d_{S}\left(u^{*}, T u\right)=d_{S}(A, B)$ and $d_{S}(v, T y)=d_{S}(A, B)$, then we get $u=u^{*}=$ $v=6, x=2,6$, and $y=2,6$. Now since $u=u^{*}=v=6, \varphi(S(u, u, v))=0$. Hence,

$$
\begin{aligned}
& F\left(\varphi\left(m_{\left(u . u^{*}, v, x, y\right)}\right), \psi\left(m_{\left(u, u^{*}, v, x, y\right)}\right)\right)-\varphi(S(u, u, v)) \\
& \quad=\varphi\left(m_{\left(u, u^{*}, v, x, y\right)}\right)-\frac{\psi\left(m_{\left(u, u^{*}, v, x, y\right)}\right)}{\psi\left(m_{\left(u, u^{*}, v, x, y\right)}\right)+k}-S(u, u, v) \\
& \quad \geq \varphi\left(m_{\left(u, u^{*}, v, x, y\right)}\right)-\psi\left(m_{\left(u, u^{*}, v, x, y\right)}\right)-0 \\
& \quad=m_{\left(u, u^{*}, v, x, y\right)}-\frac{1}{2} m_{\left(u, u^{*}, v, x, y\right)} \geq 0
\end{aligned}
$$

where $F \in \mathcal{C}, \varphi \in \Phi, \psi \in \Phi_{u}$ and

$$
m_{\left(u, u^{*}, v, x, y\right)}=\frac{1}{a+b+c+d}\left[a S(u, u, x)+b S(x, x, y)+c S\left(y, y, u^{*}\right)+d S(y, y, v)\right]
$$

with $a, b, c, d \geq 0$ and $a+b+c+d>0$.

Therefore, we have

$$
\varphi(S(u, u, v)) \leq F\left(\varphi\left(m_{\left(u, u^{*}, v, x, y\right)}\right), \psi\left(m_{\left(u, u^{*}, v, x, y\right)}\right)\right) .
$$

That is,

$$
\left.\begin{array}{l}
d_{S}(u, T x)=d_{S}(A, B) \\
d_{S}\left(u^{*}, T u\right)=d_{S}(A, B) \\
d_{S}(v, T y)=d_{S}(A, B)
\end{array}\right\} \Rightarrow \varphi(S(u, u, v)) \leq F\left(\varphi\left(m_{\left(u, u^{*}, v, x, y\right)}\right), \psi\left(m_{\left(u, u^{*}, v, x, y\right)}\right)\right) .
$$

Thus $T$ is an $S$ - $(F, \varphi, \psi)$-sum-proximal contractive mapping. All the conditions of Theorem 2.6 hold true and $T$ has a unique best proximity point. Here, $z=6$ is the unique best proximity point of $T$.

Remark 2.8 If we take $F(s, t)=(a+b+c+d) s, 0<a+b+c+d<1$ and $\varphi(t)=t$ in Theorem 2.6, then our result reduces to Theorem 2.6 in [35]. 
Theorem 2.9 Let $A, B$ be two nonempty subsets of an $S$-metric space $(X, S)$ such that $(A, S)$ is a complete $S$-metric space, $A_{0}$ is nonempty, and $B$ is approximately compact with respect to $A$. Assume that $T: A \rightarrow B$ is a nonself-mapping such that $T\left(A_{0}\right) \subseteq B_{0}$ and, for $x, y, u, v \in$ $A$,

$$
\left.\begin{array}{l}
d_{S}(u, T x)=d_{S}(A, B) \\
d_{S}(v, T y)=d_{S}(A, B)
\end{array}\right\} \quad \Rightarrow \quad \varphi(S(u, u, v)) \leq F\left(\varphi\left(m_{(u, v, x, y)}\right), \psi\left(m_{(u, v, v, y)}\right)\right)
$$

where $F \in C, \varphi \in \Phi, \psi \in \Phi_{u}$ and

$$
\begin{aligned}
m_{(u, v, x, y)}= & \frac{1}{a+b+c+d} \\
& \times\left[a S(x, x, u)+b \sqrt{\frac{S(x, x, y) S(x, x, u)}{1+S(u, u, v)}}+c S(x, x, y)+d S(x, x, u)\right]
\end{aligned}
$$

with $a, b, c, d \geq 0$ and $a+b+c+d>0$. Then $T$ has a unique best proximity point.

Proof Following the same lines as those in the proof of Theorem 2.3, we can construct a sequence $\left\{x_{n}\right\}$ in $A_{0}$ satisfying

$$
d_{S}\left(x_{n+1}, T x_{n}\right)=d_{S}(A, B), \quad \forall n \in \mathbb{N} \cup\{0\} .
$$

From (43) with $x=x_{n-1}, u=x_{n}, y=x_{n}$ and $v=x_{n+1}$, we have

$$
\begin{aligned}
& \varphi\left(S\left(x_{n}, x_{n}, x_{n+1}\right)\right) \\
& \leq F\left(\varphi \left(\frac { 1 } { a + b + c + d } \left[a S\left(x_{n-1}, x_{n-1}, x_{n}\right)\right.\right.\right. \\
&+b \sqrt{\frac{S\left(x_{n-1}, x_{n-1}, x_{n}\right) S\left(x_{n-1}, x_{n-1}, x_{n}\right)}{1+S\left(x_{n}, x_{n}, x_{n+1}\right)}} \\
&\left.\left.+c S\left(x_{n-1}, x_{n-1}, x_{n}\right)+d S\left(x_{n-1}, x_{n-1}, x_{n}\right)\right]\right), \\
& \psi\left(\frac { 1 } { a + b + c + d } \left[a S\left(x_{n-1}, x_{n-1}, x_{n}\right)\right.\right. \\
&+ b \sqrt{\frac{S\left(x_{n-1}, x_{n-1}, x_{n}\right) S\left(x_{n-1}, x_{n-1}, x_{n}\right)}{1+S\left(x_{n}, x_{n}, x_{n+1}\right)}} \\
&\left.\left.\left.+c S\left(x_{n-1}, x_{n-1}, x_{n}\right)+d S\left(x_{n-1}, x_{n-1}, x_{n}\right)\right]\right)\right) \\
& \leq \varphi\left(S\left(x_{n-1}, x_{n-1}, x_{n}\right)\right)
\end{aligned}
$$

for all $n \in \mathbb{N} \cup\{0\}$. This implies

$$
S\left(x_{n}, x_{n}, x_{n+1}\right) \leq S\left(x_{n-1}, x_{n-1}, x_{n}\right)
$$

So, the sequence $\left\{S\left(x_{n}, x_{n}, x_{n+1}\right)\right\}$ is a decreasing sequence in $\mathbb{R}^{+}$and thus it is convergent to $t \in \mathbb{R}^{+}$. We claim that $t=0$. Suppose, on the contrary, that $t>0$. Taking limit as $n \rightarrow \infty$ 
in (46), we get

$$
\varphi(t) \leq F(\varphi(t), \psi(t))
$$

which implies $\varphi(t)=0$ or $\psi(t)=0$. That is, $t=0$ which is a contradiction. Hence, $t=0$. That is,

$$
\lim _{n \rightarrow \infty} S\left(x_{n}, x_{n}, x_{n+1}\right)=0 .
$$

Similarly, one can see that $\left\{x_{n}\right\}$ is a Cauchy sequence in an $S$-metric space $(X, S)$. Due to the completeness of $(A, S)$, there exists $z \in A$ such that $\left\{x_{n}\right\}$ converges to $z$. As in the proof of Theorem 2.3, we have $d_{S}(w, T z)=d_{S}(A, B)$ for some $w \in A_{0}$. Now, from (43) with $x=x_{n-1}$, $u=x_{n}, y=z$ and $v=w$, we deduce

$$
\begin{aligned}
& \varphi\left(S\left(x_{n}, x_{n}, w\right)\right) \\
& \leq F\left(\varphi \left(\frac { 1 } { a + b + c + d } \left[a S\left(x_{n-1}, x_{n-1}, x_{n}\right)\right.\right.\right. \\
&+b \sqrt{\frac{S\left(x_{n-1}, x_{n-1}, z\right) S\left(x_{n-1}, x_{n-1}, x_{n}\right)}{1+S\left(x_{n}, x_{n}, w\right)}} \\
&\left.\left.+c S\left(x_{n-1}, x_{n-1}, z\right)+d S\left(x_{n-1}, x_{n-1}, x_{n}\right)\right]\right), \\
& \psi\left(\frac { 1 } { a + b + c + d } \left[a S\left(x_{n-1}, x_{n-1}, x_{n}\right)\right.\right. \\
&+b \sqrt{\frac{S\left(x_{n-1}, x_{n-1}, z\right) S\left(x_{n-1}, x_{n-1}, x_{n}\right)}{1+S\left(x_{n}, x_{n}, w\right)}} \\
&\left.\left.\left.+c S\left(x_{n-1}, x_{n-1}, z\right)+d S\left(x_{n-1}, x_{n-1}, x_{n}\right)\right]\right)\right) .
\end{aligned}
$$

By taking the limit as $n \rightarrow \infty$ in the above inequality, we get $S(z, z, w)=0$; that is, $z=w$. Hence, $d_{S}(z, T z)=d_{S}(w, T z)=d_{S}(A, B)$; that is, $T$ has a best proximity point. To prove uniqueness, assume that $p \neq q$, such that $d_{S}(p, T p)=d_{S}(A, B)$ and $d_{S}(q, T q)=d_{S}(A, B)$. Now, by (43) with $x=u=p$ and $y=v=q$, we have

$$
\begin{aligned}
S(p, p, q) \leq & a S(p, p, p)+b \frac{\sqrt{S(p, p, q) S(p, p, p)}}{1+S(p, p, q)} \\
& +c S(p, p, q)+d S(p, p, p),
\end{aligned}
$$

which implies $S(p, p, q)=0$. Hence, $p=q$; that is, $T$ has a unique best proximity point.

Remark 2.10 By taking $F(s, t)=(a+b+c+d) s, 0<a+b+c+d<1$ and $\varphi(t)=t$ in Theorem 2.9, our result reduces to Theorem 2.7 in [35]. 


\section{Competing interests}

The authors declare that they have no competing interests.

\section{Authors' contributions}

All the authors contributed equally in the writing of this paper. All authors read and approved the manuscript.

\section{Author details}

${ }^{1}$ Department of Mathematics, Karaj Branch, Islamic Azad University, Karaj, Iran. ${ }^{2}$ Department of Mathematics, Faculty of Science, Lampang Rajabhat University, Lampang, 52100, Thailand.

\section{Publisher's Note}

Springer Nature remains neutral with regard to jurisdictional claims in published maps and institutional affiliations.

Received: 10 February 2017 Accepted: 7 June 2017 Published online: 17 June 2017

\section{References}

1. Fan, K: Extensions of two fixed point theorems of F.E. Browder. Math. Z. 112, 234-240 (1969)

2. Sadiq Basha, S, Veeramani, P: Best approximations and best proximity pairs. Acta Sci. Math. 63, 289-300 (1997)

3. Beer, G, Pai, DV: The prox map. J. Math. Anal. Appl. 156, 428-443 (1991)

4. Beer, G, Pai, DV: Proximal maps, prox maps and coincidence points. Numer. Funct. Anal. Optim. 11, $429-448$ (1990)

5. Prolla, JB: Fixed point theorems for set valued mappings and existence of best approximations. Numer. Funct. Anal. Optim. 5, 449-455 (1982/1983)

6. Reich, S: Approximate selections, best approximations, fixed points and invariant sets. J. Math. Anal. Appl. 62, 104-113 (1978)

7. Sehgal, SM, Singh, SP: A generalization to multifunctions of Fan's best approximation theorem. Proc. Am. Math. Soc. 102, 534-537 (1988)

8. Abkar, A, Gabeleh, M: Best proximity points for cyclic mappings in ordered metric spaces. J. Optim. Theory Appl. 151, 418-424 (2011)

9. Al-Thagafi, MA, Shahzad, N: Best proximity pairs and equilibrium pairs for Kakutani multimaps. Nonlinear Anal. 70(3), 1209-1216 (2009)

10. Al-Thagafi, MA, Shahzad, N: Convergence and existence results for best proximity points. Nonlinear Anal. 70(10), 3665-3672 (2009)

11. Di Bari, C, Suzuki, T, Vetro, C: Best proximity points for cyclic Meir-Keeler contractions. Nonlinear Anal. 69, 3790-3794 (2008)

12. Eldered, AA, Veeramani, P: Existence and convergence of best proximity points. J. Math. Anal. Appl. 323, 1001-1006 (2006)

13. Karapinar, E: Best proximity points of cyclic mappings. Appl. Math. Lett. 25(11), 1761-1766 (2012)

14. Karapinar, E: Best proximity points of Kannan type cyclic weak $\phi$-contractions in ordered metric spaces. An. Ştiinţ. Univ. 'Ovidius' Constanţa 20(3), 51-64 (2012)

15. Raj, VS: A best proximity point theorem for weakly contractive non-self mappings. Nonlinear Anal. 74(14), 4804-4808 (2011)

16. Sadiq Basha, S: Extensions of Banach's contraction principle. Numer. Funct. Anal. Optim. 31(5), 569-576 (2010)

17. Sadiq Basha, S: Best proximity point theorems generalizing the contraction principle. Nonlinear Anal. 74(17), 5844-5850 (2011)

18. Sadiq Basha, S: Best proximity point theorems: an exploration of a common solution to approximation and optimization problems. Appl. Math. Comput. 218(19), 9773-9780 (2012)

19. Vetro, C: Best proximity points: convergence and existence theorems for P-cyclic mappings. Nonlinear Anal. 73(7), 2283-2291 (2010)

20. Mustafa, Z, Sims, B: A new approach to generalized metric spaces. J. Nonlinear Convex Anal. 7(2), 289-297 (2006)

21. Amini-Harandi, A: Best proximity points for proximal generalized contractions in metric spaces. Optim. Lett. 7, 913-921 (2013)

22. Amini-Harandi, A, Hussain, N, Akbar, F: Best proximity point results for generalized contractions in metric spaces. Fixed Point Theory Appl. 2013, Article ID 164 (2013)

23. Aydi, H, Karapinar, E, Salimi, P: Some fixed point results in GP-metric spaces. J. Appl. Math. 2012, Article ID 891713 (2012)

24. Hussain, N, Karapinar, E, Salimi, P, Vetro, P: Fixed point results for $G^{m}$-Meir-Keeler contractive and G- $(\alpha, \psi)$-Meir-Keeler contractive mappings. Fixed Point Theory Appl. 2013, Article ID 34 (2013)

25. Mustafa, Z, Parvaneh, V, Abbas, M, Roshan, JR: Some coincidence point results for generalized $(\psi, \phi)$-weakly contractive mappings in ordered G-metric spaces. Fixed Point Theory Appl. 2013, Article ID 326 (2013)

26. Moradlou, F, Salimi, P, Vetro, P: Some new extensions of Edelstein-Suzuki-type fixed point theorem to G-metric and G-cone metric spaces. Acta Math. Sci. Ser. B Engl. Ed. 33(4), 1049-1058 (2013)

27. Nantadilok, J: Tripled fixed point theorems for generalized contractive mappings in partially ordered G-metric spaces. J. Nonlinear Convex Anal. 16(1), 151-166 (2015)

28. Razani, A, Parvaneh, V: On generalized weakly G-contractive mappings in partially ordered G-metric spaces. Abstr. Appl. Anal. 2012, Article ID 701910 (2012)

29. Sedghi, S, Shobe, N, Zhou, H: A common fixed point theorem in D*-metric spaces. Fixed Point Theory Appl. 2007, Article ID 27906 (2007)

30. Sedghi, S, Rao, KPR, Srinivsa, N: Common fixed point theorems for six weakly compatible mappings in $D^{*}$-metric spaces. Int. J. Math. Sci. 6, 225-237 (2007)

31. Dhage, BC: Generalized metric spaces mappings with fixed point. Bull. Calcutta Math. Soc. 84, $329-336$ (1992) 
32. Sedghi, S, Shobe, N, Aliouche, A: A generalization of fixed point theorems in S-metric spaces. Mat. Vesn. 64, 258-266 (2012)

33. Ansari, $\mathrm{AH}$ : Note on ' $\varphi-\psi$-contractive type mappings and related fixed point'. In: The 2 nd Regional Conference on Mathematics and Applications, Payame Noor University, pp. 377-380 (2014)

34. Ansari, AH, Kaewcharoen, A: C-Class functions and fixed point theorems for generalized $\alpha-\eta-\psi-\varphi$-F-contraction type mappings in $\alpha$ - $\eta$-complete metric spaces. J. Nonlinear Sci. Appl. 9, 4177-4190 (2016)

35. Nantadilok, J: Best proximity point results in S-metric spaces. Int. J. Math. Anal. 10(27), 1333-1346 (2016)

36. Hieu, NT, Thanh Ly, NT, Dung, NV: A generalization of Ćirić quasi-contractions for maps on S-metric spaces. Thai J. Math. 13, 369-380 (2014)

37. Bakhtin, IA: The contraction principle in quasimetric spaces. Funct. Anal., Ulianowsk, Gos. Ped. Ins. 30, 26-37 (1989)

38. Sedghi, S, Dung, NV: Fixed point theorems on S-metric spaces. Mat. Vesn. 66, 113-124 (2014)

39. Khan, MS, Swaleh, M, Sessa, S: Fixed point theorems by altering distances between the points. Bull. Aust. Math. Soc. 30(1), 1-9 (1984)

\section{Submit your manuscript to a SpringerOpen ${ }^{\mathcal{O}}$} journal and benefit from:

- Convenient online submission

- Rigorous peer review

- Open access: articles freely available online

- High visibility within the field

- Retaining the copyright to your article

Submit your next manuscript at $\gg$ springeropen.com 